This journal is the official publication of Bangladesh Society of Physiologists (BSP)

Web URL: www.banglajol.info/index.php/JBSP

Abstracted /indexed in Index Copernicus, Director of Open Access Journal, Index Medicus for South East Asia Region, Google Scholar, 12OR, infobse index, Open J gate, Cite factor, Scientific indexing services

pISSN-1983-1213; e-ISSN-2219-7508

\title{
Article
}

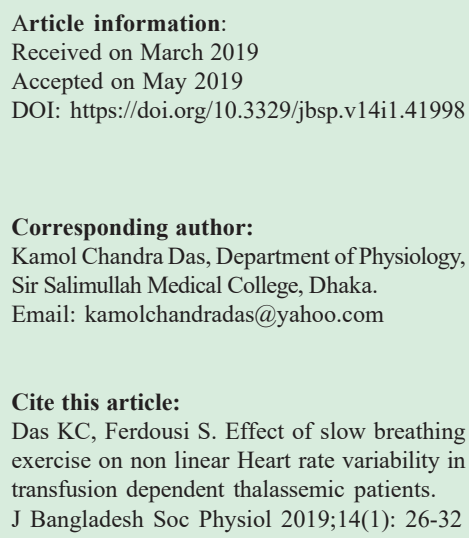

This article is open access licensed under CC BY NC SA which allows readers copy, distribute, display, and perform the work and make derivative works based on it only for noncommercial purposes.

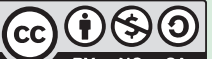

\section{Effect of slow breathing exercise on non linear Heart rate variability in transfusion dependent thalassemic patients}

\section{Kamol Chandra Das ${ }^{1}$, Sultana Ferdousi ${ }^{2}$}

1. Department of Physiology, Sir Salimullah Medical college

2. Department of Physiology, Bangabandhu Sheikh Mujib Medical University

Abstract:

Background: Nonlinear measure of heart rate variability (HRV) is an emerging tool to detect changes in cardiac autonomic nerve function (CANF) in transfusion dependent thalassemic (TDT) patients. Slow breathing exercise (SBE) can significantly improve HRV in health and various diseases. Objective: To observe the effect of slow breathing exercise (SBE) on non linear measures of HRV in TDT patients. Methods: This prospective interventional study was done in the Department of Physiology, Bangabandhu Sheikh Mujib Medical University (BSMMU), Dhaka in 2018 on 60 male TDT patients aged $15-30$ years. Thirty patients received conventional treatment and 30 patients performed slow breathing exercise along with the conventional treatment for 3 months. Age and sex matched 30 healthy control were enrolled. All subjects were followed up at baseline and after 3 months. Non linear (Poincare) HRV parameters were recorded by Power Lab 8/35 AD Instrument, Australia. For statistical analysis paired sample ' $t$ ' test and independent sample ' $t$ ' test were used. Result: SD1, SD2 and SD1/SD2 were found significantly lower in TDT patients compared to healthy control at baseline. After 3 months of slow breathing exercise, significant increment of these parameters occurred with trend of improvement in cardiac autonomic nerve function in this group of patients. Conclusion: Slow breathing exercise may improve cardiac autonomic nerve function and sympathovagal balance in transfusion dependent thalassemic patients.

Keywords: SBE, HRV non linear, TDT 
Introduction

$\mathbf{T}$

halassemia is the most common genetic blood disease in the world. About 150 million people carry the thalassemia gene globally ${ }^{1}$. About six thousand children are born annually with thalassemia in Bangladesh ${ }^{2-3}$. As anemia is the major clinical feature of thalassemia as a result of ineffective erythropoiesis \& extramedullary hemolysis, these patients require regular blood transfusion to sustain their life and therefore they become transfusion dependent thalassemic patients ${ }^{4,5}$. Following massive and repeated blood transfusion, iron overload becomes a therapeutic problem in TDT patients ${ }^{6}$. The serious consequence of iron deposition in heart causing cardiotoxicity, cardiomyopathy is the common cause of death among these patients $^{7-8}$. Reduced HRV was found consistent with a higher risk of arrhythmias after myocardial infarction and heart failure in TDT patients 9 . Silvilairat and his colleagues evaluated cardiac autonomic nerve function in thalassemic patients and observed depressed HRV in them ${ }^{10}$.

HRV is a widely used technique for assessing cardiac autonomic tone in diabetes and other cardiovascular diseases ${ }^{11-14}$. Among different geometric methods used for HRV analysis, Poincaré analysis is the most commonly used nonlinear measure for interpretation of HRV signals $^{12,15}$. In this plotting, two adjacent RR interval represent one point in the plot. The first $\mathrm{RR}$ interval is plotted in $\mathrm{X}$ axis and the next is plotted in the $\mathrm{Y}$ axis. By constructing an ellipse over the discrete distribution of Poincaré data, the HRV can be quantitatively analyzed. Mostly, three indices are measured from these plots: the standard deviation of short-term R-R interval variability (minor axis of the cloud, SD1), the standard deviation of the long-term R-R interval variability (major axis of the cloud, SD2) and the axes ratio (SD1/SD2) ${ }^{13}$. SD1, SD2 and SD1/SD2 represent parasympathetic activity, sympathetic activity and sympathovagal balance respectively ${ }^{13,16-17}$. SBE is one kind of yoga in which voluntary regulation of breathing through alternate nostrils is done in order to regulate rhythmical respiration and to keep the mind calm. SBE has important role on autonomic balance by increasing parasympathetic activity and decreasing sympathetic activity ${ }^{18}$. This exercise improves CANF by increasing parasympathetic activity or decreasing sympathetic activity in some diseases and also in normal healthy person ${ }^{19-20}$. Though several studies investigated effect of SBE on autonomic function in other diseases but there is no published report investigating the effect of SBE on nonlinear measures of HRV in TDT patients. Therefore this study aimed to evaluate the effect of SBE on nonlinear measures(poincaré plot) of HRV in TDT patients so that SBE can be used as an adjunct to conventional treatment and improve CANF as well as reduce the risk of cardiovascular complications.

\section{Methods}

This prospective interventional study was carried out in the year 2018 at the Department of Physiology, BSMMU, Shahbag, Dhaka to observe cardiac autonomic nerve function by assessing nonlinear measures of HRV in 60 male diagnosed TDT patients, aged 15-30 years. These patients were subdivided equally into 30 patients assigned with slow breathing exercise and 30 patients without slow breathing exercise in addition to conventional treatment. For comparison 30 apparently healthy subjects were taken as control.

The patients were enrolled from the outpatient Department of Transfusion Medicine and Hematology, BSMMU by purposive sampling and the controls were selected from the community of Dhaka city. The protocol of this study was approved by the Institutional Review Board of BSMMU. After briefing about the study, informed written consent was taken from each subject.

All patients were studied at baseline before intervention and the same patients were studied 
after 3 months assigned with or without SBE. Similarly healthy subjects were studied at baseline and after 3 months. All the subjects were free from respiratory disease, renal disease, diabetes mellitus, thyroid disorder and other hematological diseases. After enrollment the subjects were advised to follow some instructions on the previous night of HRV test day. They were advised to finish their meal by 9:00 pm on the previous night, to remain free from any type of stress and not to take any sedative hypnotic medication. They were requested to take a light breakfast without tea and coffee and to attend the autonomic nerve function test laboratory in the Department of Physiology, BSMMU between 8:00 am to 10:00 am on the test day. A thorough physical examination was done and pulse, BP, height, weight were measured and BMI was calculated. The subject was advised to take rest for 15-20 minutes in a controlled laboratory environment. During this period he was not allowed to talk, eat or drink, to perform physical or mental activity or sleep. ECG was recorded on lead II for 5 minutes by data acquisition device Power Lab 8/35 (AD Instrument, Australia). HRV recording was analyzed by Lab chart software. Patients were trained with the steps of SBE and advised to exercise it in a sitting position everyday in the morning and evening for half an hour for consecutive three months. For recording the exercise, a diary with time schedules including the pictures and procedures of SBE in Bangla were provided. Patients were monitored by frequent home visits if possible, during their appointment in the hospital for blood transfusion and also were contacted 3-5 times per week via telephone calls. Patients were advised to come for follow up assessment after 3 months to the same Department.

Data were expressed as Mean $\pm \mathrm{SE}$ and percentage. Statistical analysis was done using SPSS version 16 and Microsoft Excel 2007. Paired sample ' $t$ ' test and independent sample ' $t$ ' test were done, $p$ value of $<0.05$ was considered as statistically significant.

\section{Result}

In this study, all TDT patients were similar to healthy control by age and waist hip ratio but not by BMI and MUAC. But all these parameters were similar in SBE and non SBE patients (Table I). In this study, at baseline, pulse rate was significantly $(\mathrm{p}<0.001)$ higher and SBP, DBP, SD1, $\mathrm{SD} 2$ and SD1/SD2 were significantly $(\mathrm{p}<0.001)$ lower in TDT of both groups compared to control. Again no significant differences in all these parameters were observed between SBE and non SBE patients at baseline (Table II).

After 3 months follow up, TDT patients without SBE had similar pattern of these parameters when compared to their baseline values, whereas after three months of SBE, mean value of pulse rate was significantly $(p<0.01)$ decreased but SD1, $\mathrm{SD} 2$ and $\mathrm{SD} 1 / \mathrm{SD} 2$ was significantly $(\mathrm{p}<0.001$, $\mathrm{p}<0.01$ and $\mathrm{p}<0.001$ respectively) increased in these patients (Table III). Again post intervention values of all these parameters showed different trends in SBE group compared to their non SBE counterparts and they were statistically significant. Though after 3 months of followup, pulse rate, SD1 and SD2 in SBE group were significantly different from control, SD1/SD2 reached close to control value (Table IV).

Table I: Age, BMI, Waist Hip ratio and MUAC (n=70)

\begin{tabular}{lccc}
\hline Parameter & Control $(\mathrm{n}=24)$ & Non SBE $(\mathrm{n}=22)$ & $\mathrm{SBE}(\mathrm{n}=24)$ \\
\hline Age $($ years $)$ & $18.75 \pm 0.84$ & $19.4 \pm 0.88$ & $18.75 \pm 0.81$ \\
BMI $\left(\mathrm{kg} / \mathrm{m}^{2}\right)$ & $19.53 \pm 0.47$ & $15.89 \pm 0.39^{* * *}$ & $15.87 \pm 0.37^{* * *}$ \\
Waist Hip ratio & $0.86 \pm 0.02$ & $0.86 \pm 0.02$ & $0.86 \pm 0.01$ \\
MUAC $(\mathrm{cm})$ & $25.54 \pm 0.47$ & $20.36 \pm 0.61^{* * *}$ & $20.20 \pm 0.51^{* * *}$ \\
\hline
\end{tabular}

Data were expressed as mean $\pm \mathrm{SE}$. Statistical analysis was done by independent sample $\mathrm{t}$ test. BMI=Body mass index, MUAC $=$ mid upper arm circumference. ${ }^{* * *} \mathrm{p}<0.001(*$ non SBE and SBE TDT baseline vs Control baseline). 
Table II: Baseline values of and pulse rate, blood pressure (BP) and nonlinear measures in different groups $(\mathrm{n}=70)$

\begin{tabular}{lccc}
\hline Parameter & Control $(\mathrm{n}=24)$ & Non SBE $(\mathrm{n}=22)$ & $\mathrm{SBE}(\mathrm{n}=24)$ \\
\hline Pulse rate (beats/min) & $70.00 \pm 1.69$ & $90.09 \pm 2.17^{* * *}$ & $87.9 \pm 2.31^{* * *}$ \\
SBP (mm of Hg) & $116.75 \pm 1.06$ & $101.55 \pm 1.74^{* * *}$ & $100.58 \pm 1.9^{* * *}$ \\
DBP (mm of Hg) & $74.58 \pm 1.15$ & $63.45 \pm 1.08^{* * *}$ & $62.92 \pm 1.84^{* * *}$ \\
SD1 & $34.76 \pm 3.37$ & $11.24 \pm 1.56^{* * *}$ & $11.61 \pm 1.29^{* * *}$ \\
SD2 & $62.81 \pm 4.12$ & $28.6 \pm 2.62^{* * *}$ & $30.57 \pm 2.54^{* * *}$ \\
SD1/SD2 & $0.55 \pm 0.03$ & $0.37 \pm 0.03^{* * *}$ & $0.36 \pm 0.02^{* * *}$ \\
\hline
\end{tabular}

Data were expressed as mean \pm SE. Statistical analysis was done by independent sample t test. $\mathrm{SBP}=$ Systolic blood pressure, $\mathrm{DBP}=$ Diastolic blood pressure, $\mathrm{SD} 1=$ Standard deviation of short term RR interval variability, $\mathrm{SD} 2=$ Standard deviation of long term RR interval variability, SD1/SD2 ratio= Ratio of short term and long term RR interval variability. ${ }^{* * *} \mathrm{p}<0.001\left({ }^{*}\right.$ non SBE and SBE TDT baseline vs Control baseline).

Table III: Pre and post intervention values of pulse rate and blood pressure (BP) and nonlinear measures in different groups $(\mathrm{n}=70)$

\begin{tabular}{|c|c|c|c|c|}
\hline \multirow[t]{2}{*}{ Parameter } & \multicolumn{2}{|c|}{ Non $\operatorname{SBE}(n=22)$} & \multicolumn{2}{|c|}{$\operatorname{SBE}(n=24)$} \\
\hline & Pre & Post & Pre & Post \\
\hline Pulse rate (beats/min) & $90.09 \pm 2.17$ & $90.82 \pm 2.2$ & $87.9 \pm 2.31$ & $82.42 \pm 2.1^{\text {*** }}$ \\
\hline $\mathrm{SBP}(\mathrm{mm}$ of $\mathrm{Hg})$ & $101.55 \pm 1.74$ & $102.82 \pm 1.21$ & $100.58 \pm 1.9$ & $101.25 \pm 1.91$ \\
\hline $\mathrm{DBP}(\mathrm{mm}$ of $\mathrm{Hg})$ & $63.45 \pm 1.08$ & $64.36 \pm 0.91$ & $62.92 \pm 1.84$ & $63.08 \pm 1.79$ \\
\hline SD1 & $11.24 \pm 1.56$ & $11.00 \pm 1.48$ & $11.61 \pm 1.29$ & $17.63 \pm 1.6^{* * *}$ \\
\hline $\mathrm{SD} 2$ & $28.6 \pm 2.62$ & $27.95 \pm 2.54$ & $30.57 \pm 2.54$ & $35.18 \pm 2.1^{* *}$ \\
\hline $\mathrm{SD} 1 / \mathrm{SD} 2$ & $0.371 \pm 0.03$ & $0.374 \pm 0.03$ & $0.36 \pm 0.02$ & $0.49 \pm 0.04^{* * *}$ \\
\hline
\end{tabular}

Data were expressed as mean \pm SE. Statistical analysis was done by paired sample $t$ test. $\mathrm{SBP}=\mathrm{Systolic}$ blood pressure, $\mathrm{DBP}=$ Diastolic blood pressure, $\mathrm{SD} 1=$ Standard deviation of short term $\mathrm{RR}$ interval variability, $\mathrm{SD} 2=$ Standard deviation of long term RR interval variability, SD1/SD2 ratio= Ratio of short term and long term RR interval variability. $* * * p<0.001, * * p<0.01$ (Post SBE vs Pre SBE).

Table IV: Post follow up values of pulse rate, blood pressure (BP) and nonlinear measures in different groups $(\mathrm{n}=70)$

\begin{tabular}{lccc}
\hline Parameter & Control $(\mathrm{n}=24)$ & Non SBE $(\mathrm{n}=22)$ & $\mathrm{SBE}(\mathrm{n}=24)$ \\
\hline Pulse rate $($ beats $/ \mathrm{min})$ & $69.83 \pm 1.8$ & $90.82 \pm 2.2$ & $82.42 \pm 2.1^{* * \# \#}$ \\
SBP $(\mathrm{mm}$ of Hg) & $117.33 \pm 0.75$ & $102.82 \pm 1.21$ & $101.25 \pm 1.91^{\text {\#\# }}$ \\
DBP $(\mathrm{mm}$ of Hg) & $74.00 \pm 1.00$ & $64.36 \pm 0.91$ & $63.08 \pm 1.79^{\# \#}$ \\
SD1 & $33.95 \pm 3.01$ & $11.00 \pm 1.48$ & $17.63 \pm 1.6^{* * \# \#}$ \\
SD2 & $61.92 \pm 4.12$ & $27.95 \pm 2.54$ & $35.18 \pm 2.1^{* \# \#}$ \\
SD1/SD2 & $0.54 \pm 0.03$ & $0.374 \pm 0.03$ & $0.49 \pm 0.04^{*}$ \\
\hline
\end{tabular}

Data were expressed as mean \pm SE. Statistical analysis was done by independent sample $t$ test. $\mathrm{SBP}=$ Systolic blood pressure, $\mathrm{DBP}=$ Diastolic blood pressure, $\mathrm{SD} 1=$ Standard deviation of short term RR interval variability, $\mathrm{SD} 2=$ Standard deviation of long term RR interval variability, SD1/SD2 ratio= Ratio of short term and long term RR interval variability. ${ }^{*} \mathrm{p}<0.01,{ }^{*} \mathrm{p}<0.05(* \mathrm{SBE}$ vs non $\mathrm{SBE}$ ); \#\#\#p<0.001(\#SBE vs Control). 


\section{Discussion}

The present study assessed cardiac autonomic nerve function in diagnosed Transfusion Dependent Thalassemic (TDT) patients before and after slow breathing exercise with conventional treatment for 3 months by analysis of non linear measures of HRV and compared these results with control.

Data of this study showed lower MUAC and BMI in TDT patient groups compared to control but similar MUAC and BMI in both patients groups resembling to the observations in a similar study $^{21}$. They concluded that the low BMI and MUAC represented growth deficiencies in these group of patients compared to their healthy counterparts which might be related to the toxic effects of iron chelation therapy, low hemoglobin and high ferritin levels.

In this study, significantly higher resting pulse rate, lower SBP and DBP in patient groups compared to control group agree with other investigators reporting similar observations ${ }^{9,22}$. In patients with thalassemia cardiac output is increased as they suffer from chronic anemia which is attributed to increased cardiac dimension and heart rate. Moreover, expanded blood volume at the time of blood transfusion may cause uncontrolled stimulation of cardiac receptors with sympathetic afferents and vagal withdrawal and consequently impaired cardiac autonomic tone. Though cardiac output is increased but due to low peripheral resistance, blood pressure is decreased in these patients ${ }^{23-}$ 24

After practicing slow breathing exercise for 3 months, the significant decrement of pulse rate in patients suggests improvement of CANF. In contrast sustained higher pulse rate in patients without SBE indicate no improvement in CANF after 3 months. Thus these results obviously suggest that SBE is effective to improve CANF, but the post intervention heart rate of SBE group was not close to normal which suggests that 3 months of SBE in TDT patients could not restore parasympathetic activity enough to attain normal CANF. On the other hand, no significant changes in SBP and DBP were found after SBE in patients group. This fact might be due to small duration of SBE.

Significantly lower SD1, SD2 and SD1/SD2 in both TDT patients group compared to healthy counterpart before intervention is suggestive of impaired autonomic harmony in these patients.

Moreover, after three months performance of SBE, there was significant increment of these parameters in these patients, which points to wards improvement of autonomic harmony achieved by SBE.

On the other hand, no significant change was observed in these parameters in the patients not performing SBE which implies continued autonomic disharmony in absence of intervention. Though the value of SD1 and SD2 in SBE group after 3 months did not reach close to control but SD1/SD2 was near to control and there was no significant difference in this parameter of sympathovagal balance between SBE group and control. This finding expressed strong hint that SBE after 3 months practice may restore the sympathovagal balance close to that of healthy control.

Improvement of sympathovagal balance by SBE has been proved in many other investigations mostly in healthy subjects and also in some diseased condition. The improvement induced by SBE might have been linked to the fact that SBE improves peripheral oxygen consumption, neuronal oxygen uses and thus improved autonomic balance. This method causes increased tidal volume in lungs that trigger the inhibitory reflex by the stretch receptor located in the wall of this organ and increases parasympathetic activity. SBE also improves sympathovagal balance by enhancing central inhibitory rhythm ${ }^{18,25-26}$.

J Bangladesh Soc Physiol. 2019, June; 14(1): 26-32 


\section{Conclusion}

Based on the results of this study it can be concluded that slow breathing exercise may improve impaired autonomic function in TDT patients by increasing parasympathetic while decreasing sympathetic activity with the autonomic balance favoring parasympathetic dominance in TDT patients.

So, $\mathrm{SBE}$ is an effective measure to minimize the risk of cardiovascular disease in TDT patients. Therefore, SBE can be recommended for thalassemic patients as a part of complementary medicine to protect these patients from cardiovascular morbidity.

\section{References}

1. Mahyar A, Ayazi P, Pahlevan A, Mojabi H, Sehhat M-R, Javadi A. Zinc and copper status in children with beta-thalassemia major. Iran J Pediatr 2010; 20(3): 297-302.

2. Amin SK. Prevention of thalassemia by genetic counseling. Anwer khan Mod Med Coll J 2011; 2(2): $26-8$

3. Tahura S. Thalassemia and other Hemoglobinopathies in Bangladeshi Children. IJI. 2016; 3(4): 180-4.

4. Muncie HL, Campbell JS. Alpha and beta thalassemia. Am Fam Physician 2009; 80(4): 33944.

5. Viprakasit V \& Origa R. Genetic basis, pathophysiology and diagnosis. In: Cappellini MD, Cohen A, Porter J, Taher A, Viprakasti V $3^{\text {rd }}$, editors. Guidelines for the management of transfusion dependent thalassemia. Nicosia: TIF. 2014; p. 1427.

6. Galanello R, Origa R. Beta thalassemia. Orphanet J Rare Dis 2010; 5(11): 1-15.

7. Olivieri NF, Nathan DG, MacMillan JH, Wayne AS, Liu PP, McGee A, Martin M, Koren G, Cohen AR . Survival in medically treated patients with homozygous â-thalassemia. N Eng J Med 1994; 331: $574-8$.

8. Borgna-Pignatti C, Rugolotto S, Stefano PD, Zhao H, Cappellini MD, Vecchio GCD, Romeo MA, Forni GL, Gamberini MR, Ghilardi R, Piga A, Cnaan A. Survival \& complications in patients with thalassemia major treated with transfusion \& deferoxamine. Haematology 2004; 89: 1187-93.

9. Rutjanaprom W, Kanlop N, Charoenkwan P, Sittiwangkul R, Srichairatanakool S, Tantiworawit A, Phrommintikul A, Chattipakorn S, Fucharoen $\mathrm{S}$, Chattipakorn N. Heart rate variability in betathalassemia patients. Eur J Haemtol 2009; 83: 4839. DOI: $10.1111 / \mathrm{j} .1600-0609.2009 .01314 . x$.

10. Silvilairat S, Charoenkwan P, Saekho S, Tantiworawit A, Arintaya P, Somdet S, Chattipakorn N. Heart Rate Variability for Early Detection of Cardiac Iron Deposition in Patients with Transfusion- Dependent Thalassemia. PLOS one 2016; 11(10): 1-12. DOI: 10.1371/journal.pone. 0164300 .

11. Zahorska-Markiewicz B, Kuagowska E, Kucio C, Klin M. Heart Rate Variability in Obesity. Int J Obes.Relat Metab Disord 1993; 17(1): 21-3.

12. Task force of the European Society of Cardiology and the North American Society of pacing and electro physiology. Heart rate variability. Standards of measurement, physiological interpretation and clinical use. Circulation 1996; 93: 1043-65.

13. Acharya UR, Joseph KP, Kannathal N, Lim CM, Suri JS. Heart rate variability: a review. Med Biol Eng Comput 2006; 44: 1031-51.DOI:10.1007/ s11517-006-0119-0.

14. Billman GE. Heart rate variability- a historical perspective. Front in physiol 2011; 2(86): 110.DOI:10.3389/PHYS.2011.00086.

15. Kleiger RE, Miller JP, Bigger JT \& Moss AJ. Decreased heart rate variability and its association with increased mortality after acute myocardial infarction. Am J Cardiol 1987; 59(4): 256-62.

16. Hsu C-H, Tsai M-Y, Huang G-S, Lin T-C, Chen KP, Ho S-T, Shyu L-Y, Li C-Y. Poincare plot indexes of heart rate variability detect dynamic autonomic modulation during general anesthesia induction. Acta Anaesthesiol Taiwanica 2012; 50: 12-8.

17. Roy B, Ghatak S. Nonlinear methods to assess changes in heart rate variability in type 2 diabetic patients. Arq Bras Cardiol 2013; 101(4): 317-27. DOI: $10.5935 / \mathrm{abc} .20130181$.

18. Pal GK, Velkumary S, Madanmohan. Effect of short term practice of breathing exercises on autonomic functions in normal human volunteers. Indian J Med Res 2004; 120:115-21. 
19. Li C, Chang Q, Zhang J and Chai W. Effects of slow breathing rate on heart rate variability and arterial baroreflex sensivity in essential hypertension. Medicine 2018; 97(18): 1-4.

20. Yesmin J, Begum N and Ferdousi S. Effect on Time Domain parameters of HRV after slow breathing Exercise in Type 2 Diabetes Mellitus. J Bangladesh Soc Physiol 2017; 12(1):15-20.

21. Hammod H, Mokif T A, Al-Harbi H J. The correlation between thalassemia with body mass index and blood groups in children and adult patient in the provinence of babylon, Iraq. Ajpcr. 2018; 11(9): 509-12.

22. Veglio F, Melchio R, Rabbia F, Molino P, Genova G C, Martini G, Schiavone D, Piga A, Chiandussi L. Blood Pressure and Heart Rate in Young Thalassemia Major Patients. AJH1998; 11: 53947.
23. Kardelen F, Tezcan G, Akcurin G, Ertug H, Yesilipek A. Heart Rate Variability in Patients with Thalassemia Major. Pediatr Cardiol. 2008; 29: 935939. DOI: $10.1007 / \mathrm{s} 00246-008-9240-1$.

24. Wood J C. Cardiac complications in thalassemia major. Hemoglobin 2009; 33(S10): S81-S6.DOI: $10.3109 / 036302690903347526$.

25. Adhana R, Agarwal M, Gupta R, Dvivedi J. Effect of slow breathing training on heart rate, spontaneous respiratory rate and pattern of breathing. Int J Res Med Sci 2016; 4(4): 1027-30.

26. Joseph CN, Porta C, Casucci G, Casiraghi N, Maffeis M, Rossi M, Bernardi L. Slow Breathing Improves Arterial Baroreflex Sensitivity and Decreases Blood Pressure in Essential Hypertension. J Am Heart Asso 2005;46:714-16.DOI:10.1161/01.HYP.0000 $179581.68566 .7 \mathrm{~d}$. 